\title{
PERBEDAAN PENGARUH PENGGUNAAN TRANSTIBIAL PROSTHESIS DAN AXIAL CRUTCH TERHADAP KESEIMBANGAN PASIEN POST AMPUTASI TRANSTIBIAL
}

\author{
Nur Rachmat, Alfan Zubaidi \\ Kementerian Kesehatan Politeknik Kesehatan Surakarta Jurusan Ortotik Prostetik
}

\begin{abstract}
Transtibial Prosthesis, Walking Balance, Axilla Crutch, Post Transtibial Amputation. This study aims to determine the effect of the use of transtibial prosthesis and axial crutch on the balance of transtibial post amputation patient. This research is hoped to be beneficial to the benefit of people who have transtibial amputation in order to obtain the appropriate balance. This research method is Quantitative research, pre experiment, using research design one groups pre and post test design, where in this research there is only one group of subjects that will be measured equilibrium using prosthesis and axial crutch. Research conducted at PT. Kuspito Ortotik Prostetik. In this research, there are two variables, namely (1) dependent variable, balance, (2) independent variables are use of transtibial prosthesis and axial crutch. Data collection is done in two stages, first and second phase. In the first stage, the researcher records the client identity that has been defined as the research subject (sample), including name, gender, age, address, and examination to establish the type of patient who meets the inclusion criteria. Afterwards, measurements were made on patients using transtibial prostheses and recording the results of the treatment group in terms of their equilibrium values. In the second stage of data collection, measurements were taken in patients using axial crutch and recording the results of the treatment group in terms of their equilibrium value. The instruments used are TUG Test equipment (armrest and armrest seats, stopwatch, wall, stationery). Data were analyzed with SPSS for Win13.00 for Windows software. Test the normality of data using Shapiro-Wilk normality test. The results showed that there was a difference of effect of axial crutch with prosthesis on post amputation patient equilibrium $(0,017<0,05)$, it is also known that average equilibrium in group of axial crutch $(18,46)$ while mean balance in group Prosthesis $(20,84)$. Crutches are walking sticks, usually used in pairs that are created to regulate the balance at the time of going and sustaining the user's body. Axilla crutches are not designed to rest during support of the body. To minimize the inconvenience of using axilla crutches, a prosthesis is created which, when an amputation patient has been determined to use a prosthesis, determines the purpose of prosthetic fitting, whether functional, cosmetic or both.
\end{abstract}

Keywords: Transtibial Prosthesis, Walking Balance, Axilla Crutch, Post Transtibial Amputation

Abstrak: Transtibial Prostesis, Keseimbangan Berjalan, Kruk Axilla, Post Amputasi Transtibial. Penelitian ini bertujuan untuk mengetahui perbedaan pengaruh penggunaan transtibial prostesis dan axial crutch terhadap keseimbangan pasien post amputasi Transtibial. Penelitian ini diharapakan dapat bermanfaat memberikan manfaat 
bagi masyarakat yang mengalami amputasi transtibial dalam rangka mendapatkan keseimbangan yang sesuai. Metode penelitian ini adalah penelitian Kuantitatif, pre experiment, dengan menggunakan desain penelitian one groups pre and post test desain, dimana dalam penelitian ini hanya terdapat satu kelompok subyek yang akan diukur keseimbangannya menggunakan prosthesis anggota gerak bawah (kaki palsu) dan axial crutch. Penelitian dilakukan di PT. Kuspito Ortotik Prostetik. Dalam penelitian ini terdapat dua variabel yaitu (1) variabel terikat yaitu Keseimbangan, (2) variabel bebas penggunaan Prostesis transtibial dan axial crutch. Pengumpulan data dilakukan dalam dua tahap, tahap pertama dan tahap kedua. Pada tahap pertama, peneliti mencatat identitas klien yang telah ditetapkan sebagai subyek penelitian (sampel), meliputi nama, jenis kelamin, usia, alamat, serta melakukan pemeriksaan untuk menetapkan jenis pasien yang memenuhi kriteria inklusi. Setelah itu dilakukan pengukuran pada pasien menggunakan transtibial prostesis dan pencatatan hasil terhadap kelompok perlakuan dalam hal nilai keseimbangannya. Pada pengumpulan data tahap kedua, dilakukan pengukuran pada pasien menggunakan axial crutch dan pencatatan hasil terhadap kelompok perlakuan dalam hal nilai keseimbangannya. Instrumen yang digunakan adalah peralatan TUG Test (kursi dengan sandaran dan penyangga lengan, stopwatch, dinding, alat tulis). Data dianalisis dengan software SPSS for Win13.00 for Windows. Uji normalitas data menggunakan uji normalitas ShapiroWilk. Hasil penelitian menunjukkan bahwa terdapat perbedaan pengaruh penggunaan axial crutch dengan prosthesis pada keseimbangan pasien post amputasi $(0,017<0,05)$, hal ini juga diketahui bahwa rata-rata keseimbangan pada kelompok axial crutch $(18,46)$ sedangkan rata-rata keseimbangan pada kelompok prosthesis $(20,84)$. Kruk yaitu tongkat/ alat bantu untuk berjalan, biasanya digunakan secara berpasangan yang diciptakan untuk mengatur keseimbangan pada saat akan berjalan dan menopang tubuh penggunanya. Kruk axilla tidak dirancang untuk bisa beristirahat selama menopang tubuh. Untuk meminimalkan ketidakyamanan dalam pemakaian kruk axilla maka diciptakan suatu prosthesis dimana apabila seorang pasien paska amputasi sudah diputuskan dapat mempergunakan prostesis maka dilakukan penetapan tujuan dari prostetik fitting, apakah fungsional, kosmetik atau keduanya.

Kata Kunci: Transtibial Prostesis, Keseimbangan Berjalan, Kruk Axilla, Post Amputasi Transtibial

\section{PENDAHULUAN}

Keseimbangan dinamik adalah kemampuan tubuh menjaga keseimbangan saat melakukan gerakan atau aktifitas fungsional (Bougie, 2001). Dalam menjaga keseimbangan dinamis, peran somatosensoris adalah sebagai reseptor pada kulit, subkutan telapak kaki dan propioceptor pada otot, tendon dan sendi yang memberi informasi tentang kekuatan otot, uluran otot, ketegangan otot dan kontraksi otot, juga nyeri, suhu, tekanan dan posisi sendi. Sedangkan sistem muskuloskeletal yang mempengaruhi keseimbangan yaitu kekuatan otot, daya tahan dan kelenturan. Sistem ini memungkinkan otot untuk bergerak secara sinergi, simultan dalam waktu tertentu untuk mengatasi gaya yang ada. Kelemahan otot pada kaki akan 
mempengaruhi kemampuan untuk sehingga di perlukan kontraksi otot yang adekuat sesuai aktifitas yang akan di lakukan. Otot - otot sekitar sendi bekerja ketika mempertahankan keseimbangan dan selanjutnya strategi postural akan digunakan untuk mencapai keseimbangan (Bougie, 2001). Strategi postural tidak hanya melibatkan gerak sinergi otot tetapi juga pola gerakan, joint torques dan gaya kontak (Chandler, 2000). Ada tiga strategi gerakan yang paling sering di gunakan sebagai reaksi untuk mempertahankan keseimbangan, yaitu strategi ankle, strategi hip dan strategi stapping. Strategi ankle paling sering di gunakan pada situasi dimana terjadi gangguan kecil dan pada dasar permukaan yang rata. Strategi ini membutuhkan kekuatan otot dan Lingkup Gerak Sendi (LGS) ankle yang utuh. Strategi ankle dan sinergi otot yang berhubungan merupakan pola pertama untuk mengontrol gerakan tegak. Strategi ini mempertahankan massa tubuh dalam posisi stabil melalui gerakan tubuh yang terutama berpusat pada ankle.

Salah satu cara untuk membantu para penderita cedera atau cacat kaki dalam melakukan pekerjaan atau kehidupan sehari-hari adalah dengan menggunakan kruk. Kruk yaitu tongkat/ alat bantu untuk berjalan, biasanya digunakan secara berpasangan yang diciptakan untuk mengatur keseimbangan pada saat akan berjalan dan menopang tubuh penggunanya (Kedlaya, 2008). Penggunaan Prostesis transtibial merupakan salah satu program rehabilitasi pada pasien pasca amputasi transtibial. Pasien yang telah menggunakan Prostesis transtibial dapat berjalan dengan nyaman dan seimbang. Transtibial Prostesis adalah alat pengganti anggota gerak bawah yang teramputasi. Dalam mencapai keseimbangan saat berjalan, pasien bisa menggunakan Axial Kruk maupun Transtibial Prosthesis. Penilaian keseimbangan dinamik menggunakan Time Up and Go Test (TUG Test). adalah test keseimbangan dinamis untuk mengukur kecepatan reaksi terhadap aktivitas yang memerlukan keseimbangan. Alat yang di gunakan adalah sebuah kursi dengan sandaran dan penyangga lengan, stopwatch dan dinding (Wall et al, 2000).

\section{METODE PENELITIAN}

Penelitian dilakukan di PT. Kuspito Ortotik Prostetik. Dalam penelitian ini terdapat dua variabel yaitu (1) variabel terikat yaitu Keseimbangan, (2) variabel bebas penggunaan Prostesis transtibial dan axial crutch. Pengumpulan data dilakukan dalam dua tahap, tahap pertama dan tahap kedua. Pada tahap pertama, peneliti mencatat identitas klien yang telah ditetapkan sebagai subyek penelitian (sampel), meliputi nama, jenis kelamin, usia, alamat, serta melakukan pemeriksaan untuk menetapkan jenis pasien yang memenuhi kriteria inklusi. Setelah itu dilakukan pengukuran pada pasien menggunakan transtibial prostesis dan pencatatan hasil terhadap kelompok perlakuan dalam hal nilai keseimbangannya. Pada pengumpulan data tahap kedua, dilakukan pengukuran pada pasien menggunakan axial crutch dan pencatatan hasil terhadap kelompok perlakuan dalam hal nilai keseimbangannya. Instrumen yang digunakan adalah peralatan TUG Test (kursi dengan sandaran dan penyangga lengan, stopwatch, dinding, alat tulis). Data dianalisis dengan software SPSS for Win13.00 for Windows. Uji normalitas 
data menggunakan uji normalitas ShapiroWilk.

\section{HASIL PENELITIAN}

1. Karakteristik Sampel Penelitian

a. Usia sampel penelitian kelompok perlakuan crutch dan prosthesis Hasil karakteristik sampel penelitian berdasarkan usia responden pada kelompok pemakaian crutch dan prosthesis dapat dilihat pada tabel 1

\section{Tabel 1}

\section{Usia Sampel Kelompok Crutch dan} Kelompok Prosthesis

\begin{tabular}{ccccc}
\hline Usia & \multicolumn{2}{c}{$\begin{array}{c}\text { Kelompok } \\
\text { Crutch }\end{array}$} & \multicolumn{2}{c}{$\begin{array}{c}\text { Kelompok } \\
\text { Prosthesis }\end{array}$} \\
\cline { 2 - 5 } $\begin{array}{c}\mathrm{N} \\
21-30\end{array}$ & 9 & 33,4 & $\mathrm{n}$ & $\%$ \\
$\begin{array}{c}\text { tahun } \\
31-40\end{array}$ & 10 & 37,0 & 10 & 37,0 \\
tahun & & & & 18,5 \\
$41-50$ & 4 & 14,8 & 9 & 33,4 \\
tahun & & 14,8 & 3 & 11,1 \\
50 tahun & 4 & & & \\
ke atas & & & 27 & 100
\end{tabular}

$\begin{array}{lllll}\text { Jumlah } & 27 & 100 & 27 & 100\end{array}$

Hasil penelitian menunjukkan

bahwa mayoritas usia sampel penelitian pada kelompok crutch maupun kelompom prosthesis berada pada kelompok usia 31 - 40 tahun yaitu sebanyak 10 orang $(37,0 \%)$.

b. Jenis kelamin sampel penelitian kelompok perlakuan crutch dan prosthesis

Hasil karakteristik sampel penelitian berdasarkan jenis kelamin responden pada kelompok pemakaian crutch dan prosthesis dapat dilihat pada tabel 2
Tabel 2

Jenis Kelamin Sampel Kelompok

Crutch dan Kelompok Prosthesis

\begin{tabular}{ccccc}
\hline $\begin{array}{c}\text { Jenis } \\
\text { Kelamin }\end{array}$ & \multicolumn{2}{c}{$\begin{array}{c}\text { Kelompok } \\
\text { Crutch }\end{array}$} & \multicolumn{2}{c}{$\begin{array}{c}\text { Kelompok } \\
\text { Prosthesis }\end{array}$} \\
\cline { 2 - 5 } & $\mathrm{N}$ & $\%$ & $\mathrm{n}$ & $\%$ \\
Laki-laki & 9 & 33,3 & 12 & 44,4 \\
Perempuan & 18 & 66,7 & 15 & 55,6 \\
Jumlah & 27 & 100 & 27 & 100 \\
\hline Hasil & \multicolumn{2}{l}{ penelitian } & \multicolumn{2}{c}{ menunjukkan }
\end{tabular}

bahwa mayoritas jenis kelamin sampel penelitian pada kelompok crutch maupun kelompom prosthesis adalah perempuan yaitu sebanyak 18 orang $(66,7 \%)$ pada kelompok perlakuan crutch dan sebanyak 15 orang $(55,6 \%)$ pada kelompok perlakuan prosthesis.

c. Pekerjaan sampel penelitian kelompok perlakuan crutch dan prosthesis

Hasil karakteristik sampel penelitian berdasarkan pekerjaan responden pada kelompok pemakaian crutch dan prosthesis dapat dilihat pada tabel 3

\section{Tabel 3}

Pekerjaan Sampel Kelompok Crutch dan Kelompok Prosthesis

\begin{tabular}{ccccc} 
Pekerjaan & \multicolumn{2}{c}{$\begin{array}{c}\text { Kelompok } \\
\text { Crutch }\end{array}$} & \multicolumn{2}{c}{$\begin{array}{c}\text { Kelompok } \\
\text { Prosthesis }\end{array}$} \\
\cline { 2 - 5 } Tidak & $\mathrm{N}$ & $\%$ & $\mathrm{n}$ & $\%$ \\
bekerja & 2 & 7,4 & 4 & 14,8 \\
Tani & - & - & 2 & 7,4 \\
Swasta & 11 & 40,7 & 13 & 48,1 \\
PNS & 14 & 51,9 & 8 & 29,6 \\
Jumlah & 27 & 100 & 27 & 100 \\
\hline Hasil & \multicolumn{2}{c}{ penelitian } & menunjukkan
\end{tabular}

bahwa mayoritas pekerjaan sampel penelitian pada kelompok crutch adalah sebagai PNS yaitu sebanyak 14 orang (51,9\%), sedangkan pada kelompok prosthesis berada pada kelompok pekerjaan sebagai swasta yaitu sebanyak 13 orang $(48,1 \%)$. 
d. Panjang stump sampel penelitian kelompok perlakuan crutch dan prosthesis

Hasil karakteristik sampel penelitian berdasarkan panjang stump responden pada kelompok pemakaian crutch dan prosthesis dapat dilihat pada tabel 4

\section{Tabel 4}

Panjang Stump Sampel Kelompok Crutch dan Kelompok Prosthesis

\begin{tabular}{ccccc}
\hline $\begin{array}{c}\text { Panjang } \\
\text { stump }\end{array}$ & \multicolumn{2}{c}{$\begin{array}{c}\text { Kelompok } \\
\text { Crutch }\end{array}$} & \multicolumn{2}{c}{$\begin{array}{c}\text { Kelompok } \\
\text { Prosthesis }\end{array}$} \\
\cline { 2 - 5 } & $\mathrm{N}$ & $\%$ & $\mathrm{n}$ & $\%$ \\
Stump & - & - & - & - \\
pendek & & & & \\
Stump & 11 & 40,7 & 13 & 48,1 \\
medium & & & 14 & 51,9 \\
Stump & 16 & 59,3 & 14 \\
panjang & & & & \\
Jumlah & 27 & 100 & 27 & 100 \\
\hline
\end{tabular}

Hasil penelitian menunjukkan bahwa mayoritas sampel penelitian memiliki panjang stump pada kelompok stump panjang yaitu pada kelompok crutch sebanyak 16 orang $(59,3 \%)$ dan kelompom prosthesis yaitu sebanyak 14 orang $(51,9 \%)$.

e. Sebab amputasi sampel penelitian kelompok perlakuan crutch dan prosthesis

Hasil karakteristik sampel penelitian berdasarkan sebab amputasi responden pada kelompok pemakaian crutch dan prosthesis dapat dilihat pada tabel 5

\section{Tabel 5}

\begin{tabular}{lcccc}
\multicolumn{3}{c}{$\begin{array}{c}\text { Sebab Amputasi Sampel Kelompok } \\
\text { Crutch dan Kelompok Prosthesis }\end{array}$} \\
\hline Sebab amputasi & \multicolumn{2}{c}{$\begin{array}{c}\text { Kelompok } \\
\text { Crutch }\end{array}$} & \multicolumn{2}{c}{$\begin{array}{l}\text { Kelompok } \\
\text { Prosthesis }\end{array}$} \\
\cline { 2 - 5 } & $\mathrm{N}$ & $\%$ & $\mathrm{n}$ & $\%$ \\
Kelainan & 5 & 18,5 & 5 & 18,5 \\
kongenital & & & 16 & 59,3 \\
Kecelakaan & 17 & 63 & 16 \\
penyakit & 5 & 18,5 & 6 & 22,2 \\
$\quad$ Jumlah & 27 & 100 & 27 & 100 \\
\hline
\end{tabular}

Hasil penelitian menunjukkan bahwa mayoritas sampel penelitian mengalami amputasi dikarena adanya kecelakaan yaitu pada kelompok crutch sebanyak 17 orang $(63,0 \%)$ sedangkan pada kelompom prosthesis berada pada kelompok kejadian 30 tahun yang lalu yaitu sebanyak 16 orang $(59,3 \%)$.

\section{Perbedaan Pengaruh Penggunaan Transtibial Prosthesis Dan Axial Crutch Terhadap Keseimbangan Pasien Post Amputasi Transtibial \\ Hasil uji normalitas dengan} kolmogorov smirnov diketahui bahwa pada kelompok axial crutch diperoleh $p$ value keseimbangan sebesar 0,289>0,05 sehingga data terdistribusi normal, sedangkan pada kelompok prosthesis diperoleh $p$ value keseimbangan sebesar $0,753>0,05$ sehingga data terdistribusi normal. Karena kedua kelompok perlakuan tersebut data terdistribusi normal maka digunakan statistik parametrik yaitu uji independent sample ttest.

Hasil penelitian perbedaan keseimbangan pada kelompok axial cructh dengan kelompok prosthesis dapat dilihat pada tabel berikut :

\section{Tabel 6}

Perbedaan Pengaruh Axial Crutc dan Prostesis terhadap Keseimbangan Pasien Post Amputasi

\begin{tabular}{clccc}
\hline Variabel & Perlakuan & Mean & $\mathrm{t}$ & $\begin{array}{c}p \\
\text { value }\end{array}$ \\
\hline Keseimbangan & $\begin{array}{l}\text { Axial } \\
\text { crutch } \\
\text { Prosthesis }\end{array}$ & 18,46 & - & 0,017 \\
& 20,84 & 2,461 & \\
\hline
\end{tabular}

Hasil penelitian menunjukkan ratarata keseimbangan pada kelompok axial crutch $(18,46)$ sedangkan rata-rata keseimbangan pada kelompok prosthesis $(20,84)$. Hasil uji statistik dengan 
independent sample t-test menunjukkan $p$ value $0,017<0,05$ sehingga terdapat perbedaan pengaruh axial crutch dan prostesis dengan keseimbangan.

\section{PEMBAHASAN}

Hasil penelitian menunjukkan bahwa terdapat perbedaan pengaruh penggunaan axial crutch dengan prosthesis pada keseimbangan pasien post amputasi $(0,017<0,05)$, hal ini juga diketahui bahwa rata-rata keseimbangan pada kelompok axial crutch $(18,46)$ sedangkan rata-rata keseimbangan pada kelompok prosthesis $(20,84)$. Dimana menjaga keseimbangan dinamis, peran somatosensoris adalah sebagai reseptor pada kulit, subkutan telapak kaki dan propioceptor pada otot, tendon dan sendi yang memberi informasi tentang kekuatan otot, uluran otot, ketegangan otot dan kontraksi otot, juga nyeri, suhu, tekanan dan posisi sendi.

Salah satu cara untuk membantu para penderita cedera atau cacat kaki dalam melakukan pekerjaan atau kehidupan sehari-hari adalah dengan menggunakan kruk. Kruk yaitu tongkat/alat bantu untuk berjalan, biasanya digunakan secara berpasangan yang diciptakan untuk mengatur keseimbangan pada saat akan berjalan dan menopang tubuh penggunanya. Kruk terbagi dua (Kedlaya, 2008) yaitu: Kruk Axilla Kruk axilla menopang badan dari ketiak sampai ke lantai, kruk axilla dapat mentransfer sampai $80 \%$ berat badan, namun akan terdapat tekanan yang besar pada bagian ketiak, karena berat badan yang bertumpu pada ketiak tadi. Kruk axilla tidak dirancang untuk bisa beristirahat selama menopang tubuh. Transtibial Prosthesis adalah
Untuk meminimalkan ketidakyamanan dalam pemakaian kruk axilla maka diciptakan suatu prosthesis dimana apabila seorang pasien paska amputasi sudah diputuskan dapat mempergunakan prostesis maka dilakukan penetapan tujuan dari prostetik fitting, apakah fungsional, kosmetik atau keduanya. Prostetik ditujukan untuk menggantikan fungsi tetapi tidak total menggantikan fungsi bagian tubuh yang telah diamputasi. Setiap komponen prostetik memberikan suatu kemampuan fungsional yang berbeda. Sebuah prostetik dapat dirancang untuk memenuhi kebutuhan khusus menyangkut kekaryaan, rekreasional atau kebutuhan sosial.

\section{KESIMPULAN DAN SARAN}

Terdapat perbedaan pengaruh penggunaan axial crutch dengan pada keseimbangan pasien post amputasi $(0,017<0,05)$, hal ini juga diketahui bahwa rata-rata keseimbangan pada kelompok axial crutch $(18,46)$ sedangkan rata-rata keseimbangan pada kelompok prosthesis $(20,84)$. Pasien yang amputasi sebaiknya segera memakai prosthesis agar bisa lebih seimbang. Dengan memakai prosthesis, pasien dapat berjalan dengan keseimbangan dinamis yang lebih baik, selain itu tangan pasien bisa bebas untuk bergerak tanpa memegang kruk, sehingga aktifitas lebih baik.

\section{DAFTAR RUJUKAN}

Bougie JD, 2001; Physical Activity And Exercise For The Older Adult, The Aging Body. McGraw-Hill : New York

Chandler, J.M., 2000; Balance and Falls in The Elderly: Issues In Evaluation and Treatment dalam Guccione, 
192 Jurnal Terpadu Ilmu Kesehatan, Volume 6, No 2,November 2017, hlm 118-240

A.A.; Geriatric Physical Therapy.

Boston: Mosby.

Dody Bactiar, Audy, Jamari, Iwan

Budiwan. Perancangan

Biomekanisme Sendi Prostesa

Untuk Pasien Amputasi Tungkai

Atas Lutut dengan Desain

Ergonomi dan Fleksibel. Prosiding

SNST ke-5 Tahun 2014

Kedlaya D., Kuang T. 2008 ; Assistive devices to improve independence. Retrieved from EMedicine via WebMD website: http://emedicine.medscape.com/art icle/325247-overview

Wall, J.C., 2000, The Timed Get-Up and Go Test Revisited: Measurement of the component task. Journal of rehabilitation Research \& Development, 37:109-114 